Article

\title{
Resilience Assessment of Lowland Plantations Using an Ecosystem Modeling Approach
}

\section{Chia-Hsin Wu ${ }^{1,2}$, Yueh-Hsin Lo ${ }^{3}$, Juan A. Blanco ${ }^{3}$ and Shih-Chieh Chang ${ }^{2, *}$}

1 Senior Vocational High School, National Taitung Junior College, 95045 Taitung, Taiwan; E-Mail:wu05@ntc.edu.tw

2 Department of Natural Resources and Environmental Studies, National Dong Hwa University, 97401 Hualien, Taiwan

3 Departamento Ciencias del Medio Natural, Universidad Pública de Navarra, Campus de Arrosadía, Pamplona, Navarra 31006, Spain; E-Mails: yuehhsin.lo@gmail.com (Y.-H.L.); juan.blanco@unavarra.es (J.A.B.)

* Author to whom correspondence should be addressed; E-Mail: scchang@mail.ndhu.edu.tw; Tel.: +886-3-863-3275; Fax: +886-3-863-3260.

Academic Editor: Yu-Pin Lin

Received: 30 December 2014 / Accepted: 25 March 2015 / Published: 31 March 2015

\begin{abstract}
As afforestation programs of former farmlands take hold in Taiwan to achieve a variety of ecological and socio-economic values, it is becoming necessary to define best forest management. Hence, we simulated mixed stands of Cinnamomum camphora and Fraxinus griffithii planted through a gradient of soil fertility and varying camphor/ash density ratios, but maintaining a fixed total stand density of 1500 trees ha ${ }^{-1}$. Total stand productivity was slightly lower in mixed stands than the combination of both monocultures in rich and poor sites. Maximum negative yield surpluses for 50-year old stands were $7 \mathrm{Mg} \mathrm{ha}^{-1}$ and $6 \mathrm{Mg} \mathrm{ha}^{-1}$ for rich and poor sites with a 1:1 camphor laurel/ash ratios. Maximum stand woody biomass in rich sites was reached in camphor laurel monocultures $\left(120 \mathrm{Mg} \mathrm{ha}^{-1}\right)$ and in poor sites for Himalayan ash monocultures $\left(58 \mathrm{Mg} \mathrm{ha}^{-1}\right)$. However, for medium-quality sites, a small yield surplus $\left(11 \mathrm{Mg} \mathrm{ha}^{-1}\right)$ was estimated coinciding with a maximum stand woody biomass of $95 \mathrm{Mg} \mathrm{ha}^{-1}$ for a 1:1 camphor laurel/ash density ratio. From an ecological resilience point of view, rotation length was more important than stand composition. Long rotations (100 years) could improve soil conditions in poor sites. In rich sites, short rotations ( 50 years) should be avoided to reduce risks or fertility loss.
\end{abstract}


Keywords: mixed forests; artificial forest; ecological modeling; resilience; ecological sustainability; camphor laurel; Himalayan ash; FORECAST model

\section{Introduction}

\subsection{Background}

The current trends of economic globalization and ageing population have an enormous impact on land use and have raised social-ecological problems in many countries around the world [1,2]. Changes in human population numbers and types of settlements have been directly linked to a decrease in forest land [3]. Rural population aging and urbanization is traditionally followed by abandonment of farmlands, Europe being the most striking example [4]. On the other hand, human population expansion and colonization still is causing important forest area losses in many tropical countries [5]. However, among tropical countries, the case of Taiwan is probably unique, as rather than dealing with an expansion of croplands and increased pressure on forests, its economic development is causing changes in the rural environment that mimic those of regions developed earlier in the 20th century, such as Europe or Japan. In Taiwan, the total agricultural land has decreased from $9200 \mathrm{~km}^{2}$ in the middle of the 1970 s to $8000 \mathrm{~km}^{2}$ in 2012 , a notable change in this small island country that has a total area of only $36,000 \mathrm{~km}^{2}$. The diminishing of agricultural land correlates well with the aging of the population, since old farmers gradually retire from farming and the newer generations have no interest in the labor-intensive work of agriculture [6]. The ageing index (the ratio of old age population (aged $>65$ ) to young population (aged $<15)$ ) of Taiwan was 5.9 one year after the end of World War II and stayed unchanged until 1960. From 1970 to the present, the tendency of population aging has kept its steady path, with an annual increasing rate of the aging index of $c a$. $6 \%$, which resulted in an aging index of 80.5 in 2013. Such a combination with a tropical developed economy makes Taiwan an ideal model for what may be expected from other tropical countries, whose economies are currently developing at accelerating speeds, such as Brazil, Colombia, Indonesia, Malaysia, India and the tropical portions of China, among others.

To promote the use of the farmlands that have been left uncultivated, the Taiwanese Ministry of Agriculture issued the "Plain Landscape Afforestation Program (PLAP)" policy in 2002, through which the afforestation on the farmlands will be encouraged by a 20 -year subsidy $[7,8]$. This is the first time since the arrival of civilization to Taiwan that large areas of the island's plain region are being subjected to afforestation management and marks a change from colonization to restoration policies that are being encouraged for implementation in other tropical countries [5]. Among others, the Taiwan Sugar Corporation (TSC) is the largest land owner joining this plantation program, because $90 \%$ of its sugarcane production has been ceased due to increasing international competition. In 2002, the company started to plant trees according to the guidelines of the PLAP policy and has about 12,000 ha planted nowadays.

The Taiwanese Ministry of Agriculture's Afforestation guidelines give land owners the freedom to choose the species to be planted from a list that includes 30 endemic broad-leaved tree species. According to the guidelines, the density of the plantation must be maintained, and regular management 
practices, including understory vegetation control, must be performed for the first 20 years after plantation establishment. Whether or not the new forest stands should be planted as mono- or mixed-species stands is not required by the government. As a result, all TSC's plantations are single-species forests, although the stands of different species are interlaced, forming a mosaic landscape.

\subsection{Restoring the Resilience of Reforested Areas}

After a decade of the execution of the plain afforestation policy, debate on the ultimate use of such plantations has become intensive, because what stakeholders expect from the outcomes of the plantations is rather diverse. The Taiwanese government forestry agency sees the increase in biodiversity through the increased habitat diversity in the plantations as the main ecosystem service that the plain afforestation program should provide. Increased forest area in the lowland region will also increase its value for carbon sequestration, ecotourism and scenic services. However, land owners, such as the Taiwan Sugar Cooperation, want to profit from selling forest products, such as timber, small trees for gardening, etc. Such a conflict of interest and expected values indicate the need for a multi-value approach to sustainable forest management at these sites [9], which is also supported by the growing environmental awareness of the public.

For forest management to be able to deliver such a broad range of ecosystem services, it is necessary to move towards adaptive forest management [10]. In adaptive forest management, it is important to maintain the ability of an ecosystem to return to its normal status after the system has been hit by a disturbance. Such an ability is a measure of ecosystem resilience [11,12]. Forest ecosystems of high resilience should therefore be an important management goal, especially for the regions prone to frequent natural disturbances, like typhoons. Among other ecological indicators of the ecosystem state, soil organic matter (SOM) is an important nutrient pool that supports the regeneration of a stand after disturbances and, therefore, could serve as an indicator of system resilience [13].

One key question that needs to be addressed when planning new plantations is to obtain estimations of stand productivity. A higher net primary productivity of a forest ecosystem provides not only energy and nutrients for the higher trophic layers of the system, but also increases the nutrient/carbon stocks in the plant biomass, which can increase ecosystem resilience to disturbances [14]. Mixed tree forests have commonly been reported as more productive than monocultures, as growth resources are used more thoroughly [15]. Many field experiments have tried to compare the productivity between multi- and mono-species plantations in different biomes, ranging from tropical to temperate and to boreal regions [16]. These results generally indicate an over-yielding of the stands with multiple planted tree species compared to the monocultures of the same species. However, such an over-yielding effect depends on the differences between the realized ecological niches of each species and how symmetrical their competitive growth strategies are [17].

When sustainable use of farmland is an issue for a country, how to practice afforestation in a reasonable way becomes a scientific question that needs thorough species-specific studies. In this study, we seek to assess the ecosystem functions of plantations consisting either of single-tree species (camphor laurel (Cinnamomum camphora (L.) J. Presl) or Himalayan ash (Fraxinus griffithii C.B. Clarke)) or of mixtures of these two species. Both species are native to Taiwan and had a wide distribution in the lowland region before the start of human cultivation. In the plain afforestation guidelines, these two 
species are recommended to be planted in farmlands for timber harvesting or for landscaping. In the plain afforestation area of the Taiwan Sugar Corporation in Hualien County (eastern Taiwan), on which this study is focused, the total afforestation area of camphor laurel and Himalayan ash is 121 ha and 591 ha, respectively. All of these stands are monocultures with a size of 0.5 to 15 ha.

Ideally, long-term field trial plots are the most suitable way to assess the potential for over-yielding in mixed forests. However, long-term research and field data on camphor laurel-Himalayan ash mixtures are not available. Given the long time scales needed to gather such data, a viable proxy is the use of ecosystem-level models that account for the key ecosystem processes that are involved in tree growth [9]. To be useful for research on mixed stands, such models need to take into account three main ecological processes involving multiple species: competition for resources, competitive reduction and facilitation [18].

A large number of forest models have been developed over the last 40 years, although in the latest few years, the hybrid models combining field data and process simulation are becoming increasingly popular (see [9,19] for detailed reviews). Among them, the model FORECAST [20] stands out, as it has been used as a management evaluation tool in many types of forest ecosystems around the world [21-27], including tropical and sub-tropical forests [28-33]. The model is specially designed to examine the impacts of different management strategies at the ecosystem level, accounting for resource competition (intra- and inter-specific) when several species (trees and understory) are present in the same stand, including natural and planted mixedwoods [34,35].

We used a modeling approach in this study, taking the advantage of its flexible way of scenario simulation, which would provide land owners with a glance at the best suitable management strategy (depending on their interests): a strategy of emergent value, but unfortunately still lacking in Taiwan. We hypothesized that the mixed plantation of the two tree species, camphor laurel and Himalayan ash, will yield a higher value of ecosystem services (particularly biomass and productivity) than the single-species stands of each of the two species. In short, the objectives of this study were: (1) to establish a stand-growth database for the two species from the literature; (2) to estimate the growth and compare the outcomes of stands with different stand density ratios of the two species by running the ecosystem-level forest growth model FORECAST; and (3) to evaluate the ecological sustainability and mixed stands' resiliency when under different management scenarios.

\section{Experimental Section}

\subsection{Study Species}

Camphor laurel (Cinnamomum camphora (L.) J. Presl) is naturally distributed throughout the subtropical regions of southern China in the provinces of Jiangxi, Guangdong, Guangxi, Hunan, Hubei, Yunnan, Zhejiang, Fujian and Hainan, as well as Korea, Vietnam, Japan (including the Ryukyu Islands) and Taiwan [36,37]. The natural habitats in which it is found include subtropical forests in southern China and in Japan, light-open pine woods of Pinus merkusii and rarely as a tall tree in broad-leaved evergreen forest [38]. Camphor laurel belongs to the Lauraceae family. According to Liao [36], two varieties are now recognized in Taiwan, according to the presence of bark knobs on the trunk in the var. nominale and an absence of knobs in the var. camphora. In Taiwan, var. camphora is 
found at low elevations in the north and south, while the var. nominale is endemic to Taiwan, occurring in scattered locations in the east and south of the island.

Camphor laurel is a large, robust evergreen tree that is capable of exceeding a height of $40 \mathrm{~m}$ and a girth of $22 \mathrm{~m}$ in southern Japan [39]. These are old-growth trees ( $>150$ years old, but they can live up to 1000 years) exhibiting signs of upper limb die-back, limb hollows and basal decay. In Taiwan, this species is confined to the lowlands, where it reaches $1200 \mathrm{~m}$.a.s.l. in the north and $1800 \mathrm{~m}$ in the south, identifying its response to the altitudinal and latitudinal temperature gradient.

Himalayan ash (Fraxinus griffithii C. B. Clarke) is a small tree of the Oleaceae family usually growing less than $20 \mathrm{~m}$ tall, and unlike most other ash trees, it does not lose its leaves during winter (i.e., it is evergreen). Himalayan ash is native to the Indian sub-continent, China and Southeastern Asia and is a timber tree in Taiwan. It can be found in dry slopes, forest margins, near villages and by rivers; from 100 to 2000 m.a.s.l in southern China (Fujian, Guangdong, Guangxi, Hainan, Hubei and Hunan) and Taiwan. It can also be found in Bangladesh, India, Indonesia, Japan (Ryukyu Islands), Myanmar, the Philippines and Vietnam.

\subsection{The FORECAST Model}

FORECAST is a management-oriented, deterministic, stand-level forest growth and ecosystem dynamics simulator that operates at annual time steps. The model simulates the dynamics of all forest carbon stocks required under the Kyoto Protocol (aboveground biomass, belowground biomass, litter, dead wood and soil organic carbon). It complies with the carbon estimation methods outlined by the IPCC [40]. The model uses a hybrid approach to vegetation growth modeling, as it merges the use of empirical data (i.e., growth and yield tables, among others, see below) modified by the simulation of the most important ecological processes [41]. This hybrid approach assumes that the best predictor of vegetation growth for a site with a given combination of climate and nutrient limitation is the observed growth itself. In other words, vegetation productivity for a given site depends on the combination of climatic, topographic and edaphic features of that site. Therefore, observed vegetation productivity is a variable that implicitly has already taken climate into account. This approach, combined with the annual time step, reduces the need for meteorological or climate input, which are not used as input variables in FORECAST. A detailed discussion of this approach and the full model has been described before $[9,20,42]$, and therefore, only a summary of the main driving function to calculate tree growth is provided here.

The model uses a mass balance approach to estimate how nutrients circulate in the ecosystem, how different tree and plant species compete for light and nutrients and how nutrient availability limits tree and plant growth together with available light in the canopy. Detailed descriptions of decomposition, tree uptake and biogeochemical cycles can be found in Kimmins, Mailly and Seely [20]. FORECAST has three application stages: (1) assembling calibration data and generating historical rates of key ecosystem processes; (2) model initialization by establishing the ecosystem condition for the beginning of a simulation run; and (3) simulation of tree and plant growth. A detailed explanation of how the model operates and the calibration data used for this application can be found in the Supplementary Information file companion to this manuscript. 


\subsection{Mixed Plantations Scenarios}

To explore the effects of different mixing densities on ecosystem productivity and interspecific competition, we created six different scenarios. Maintaining total stand density fixed at

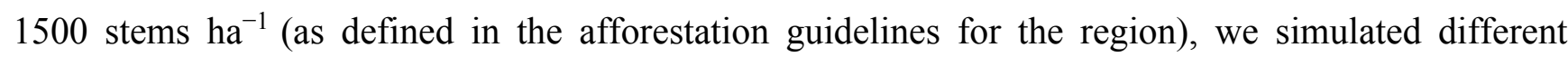
species composition by incrementing and decrementing each species densities by 200 trees per hectare for camphor laurel and Himalayan ash, from no presence $\left(0\right.$ trees $\left.\mathrm{ha}^{-1}\right)$ to monoculture (1500 trees $\left.\mathrm{ha}^{-1}\right)$. Through practical experience with monocultures, local foresters have found that this stand density maximizes tree productivity with the lowest human intervention effort. Higher densities would result in increased inter-tree competition needing thinning to avoid productivity losses, whereas lower densities would result in increased understory biomass and high competition with trees. We repeated these scenarios for three different site qualities: 17, 21 and 27, corresponding to low fertile or poor sites, medium fertile and high fertile or rich sites (measured as the site index or dominant tree height at a plantation age of 50 years). Simulations lasted for 200 years with three different rotation lengths: 50, 65 and 100 years. At the end of each rotation, the harvest of the aboveground biomass was simulated by removing $95 \%$ of the stem, $90 \%$ of the branches and $90 \%$ of the foliage from the site. The rest of the biomass was left on site as litter input. For the rotation schemes of 50 and 100 years, the number of rotations were 4 and 2, respectively, while for the 65-year rotation scheme, 3 rotations were simulated, and the simulation ended at 185 years. The target variables in this study were total stand NPP (Net Primary Production), total stand biomass, total soil organic matter and available soil N.

\subsection{Measuring Facilitation or Competition in Mixed Plantations}

When the harvest and commercial use of trees is the purpose of afforestation, the forest management will aim at maximizing the quantity of aboveground biomass, especially the stem and branch biomass. Therefore, the use yield surplus (YS) $\left(\mathrm{Mg} \mathrm{ha}^{-1}\right)$ or over-yield concept can be defined as:

$$
\mathrm{YS}_{i, y}=\left(B M_{c c, i, y}+B M_{f g, i, y}\right)-\left(B M_{c c, 1500, y} \times \frac{i}{1500}+B M_{f g, 1500, y} \times \frac{(1500-i)}{1500}\right)
$$

where $\mathrm{YS}_{i, y}$ is the yield surplus of the mixed stand in which the planting density of Cinnamomum camphora is $\mathrm{i} \mathrm{ha}{ }^{-1}$ in year y; BM is the aboveground woody tissue biomass (stem and branch); cc is Cinnamomum camphora; fg is Fraxinus griffithii. The yield surplus calculates how much the sum of the aboveground woody tissue biomass of the two tree species exceeds the "neutral value", which assumes no interspecific interaction between the two tree species. To further understand the effect of mixed planting on the biomass of each species, the value "relative yield (RY)" (\%) for Cinnamomum camphora and Fraxinus griffithii was used and defined as:

$$
\begin{gathered}
R Y_{c c, i, y}=\frac{B M_{c c, i, y}}{B M_{c c, 1500, y} \times \frac{i}{1500}} \times 100 \% \\
R Y_{f g, i, y}=\frac{B M_{f g, i, y}}{B M_{f g, 1500, y} \times \frac{1500-i}{1500}} \times 100 \%
\end{gathered}
$$


Again, the "neutral value" of the aboveground woody tissue biomass is defined as the proportion of the biomass in monoculture, where the proportion is equal to the ratio of planting density in the mixed stand (i for Cinnamomum camphora and 1500-i for Fraxinus griffithii) to that in monoculture (1500 trees $\mathrm{ha}^{-1}$ ). An RY value of higher than 100\% means that the tree species grows more harvestable aboveground wood than would be expected from the proportion of the biomass from monoculture. On the contrary, when the growth of tree species is suppressed by the other species in the mixed stand, an RY value lower than $100 \%$ will be derived.

\section{Results and Discussion}

\subsection{Model Performance}

We estimated total tree biomass at year 100 (Figure 1) ranging from 50.1 to $151.3 \mathrm{Mg} \mathrm{ha}^{-1}$ for the poor and rich sites, respectively, being $94.5 \mathrm{Mg} \mathrm{ha}^{-1}$ for the medium site. This is very similar to the reported biomass of pure camphor laurel plantations in China and Taiwan in the range of 92.52-111.08 $\mathrm{Mg} \mathrm{ha}^{-1}[43,44]$. Average productivity in camphor laurel monocultures at the poor site was $9.69 \mathrm{Mg} \mathrm{ha}^{-1} \mathrm{y}^{-1}$, very similar to values reported before [45] (9.55 $\mathrm{Mg} \mathrm{ha}^{-1} \mathrm{y}^{-1}$ ). For Himalayan ash mature plantations in Taiwan, [46] estimated total biomass ranging from 163 to $199 \mathrm{Mg} \mathrm{ha}^{-1}$. Our simulations of pure ash stands ranged from 77.9 to $155.8 \mathrm{Mg} \mathrm{ha}^{-1}$ (poor and rich sites, respectively). The lower simulated biomass was likely due to the lower density simulated than the one reported by [46] (1500 vs. $\sim 2500$ trees $^{-1} \mathrm{a}^{-1}$, respectively).

For mixed camphor laurel-Himalayan ash stands, no empirical data have been found, as this potential management option is just now being explored. Therefore, direct detailed validation of model predictions vs. field data was not possible. Previous applications of FORECAST have shown a general acceptable performance when simulating different forest types around the world: boreal [34], sub-boreal [47], temperate [26], Mediterranean [48] and tropical [29,30]. In China, it has shown good performance in sub-alpine forests [49], but more importantly, the model performed well in subtropical areas of eastern China, which share many of the ecological and floristic features of the Taiwanese site. Acceptable model performance at these sites has been reported for the simulation of both monocultures [28,31,49] and mixed stands, including Lauraceae tree species [35].

For understory simulation, field data usable for model validation are also scarce. Understory was the weakest component of the model calibration, which traditionally has received less attention than the trees. Only scarce and disperse documentation is available for understory biomass in mature forests at these sites, which also have a high variability of understory cover. Therefore, calibrating the understory component comprised a large degree of uncertainty, and evaluating model performance against independent data was not possible. Such an issue, however, should be of minor importance, as understory only accounted for a small proportion of total stand biomass and productivity (Figure 1).

\subsection{Interspecific Competition and Facilitation Processes}

The ultimate ecosystem services that human society could receive from nature are limited by the productivity of the primary producers in the ecosystems. When timber production is the primary objective of management, there is a clear tendency to favor monocultures of the most productive 
species. This is mainly because of the simpler management of monocultures (easier and less expensive establishment, planning and marketing), but also, though no less important, because less is known about planted mixed stands, the interactions between species and the most suitable management techniques [50]. In contrast, when mixed-species stands are favored, the objectives usually include wildlife conservation, aesthetics, resistance to wind damage, risk reduction or compensatory growth and protection from disease and insect outbreaks. In Taiwan, afforestation has been done mostly with monocultures due to its simplicity, but little is known about the additional potential benefits from mixed plantations. Our simulations indicate that site fertility (the major determinant of site quality) was the main variable determining the response of stand productivity to mixed camphor laurel-Himalayan ash plantations.

For the medium site quality, the accumulated net primary production within a complete rotation period of 100 years had the highest value of $1444 \mathrm{Mg} \mathrm{ha}^{-1}$ with the planting scheme of 200 camphor laurel trees ha ${ }^{-1}-1300$ ash trees $\mathrm{ha}^{-1}$ (Figure 1b). Different mixing scenarios resulted in a difference in accumulated NPP as big as $63 \mathrm{Mg} \mathrm{ha}^{-1}$. The monoculture of camphor laurel delivered the lowest accumulated stand NPP (trees plus understory) within this 100-year period of growth. The discrepancy between mixing scenarios in annual NPP steadily grew with stand aging. Shortly before the harvest at year 100, the annual NPP of the camphor laurel stand was $16.0 \mathrm{Mg} \mathrm{ha}^{-1} \mathrm{y}^{-1}$, which was $15 \%$ lower than that in the 400 camphor-1100 ash trees ha ${ }^{-1}$ mixed stand.

For the rich site quality, accumulated NPP showed a different picture, not only with a significantly higher average value than for the medium site, but also the camphor laurel monoculture provided the highest NPP compared to other mixing ratios (Figure 1a). On the contrary, the Himalayan ash monoculture was more productive than other mixing scenarios, when they were planted in poor sites with less favorable growth conditions (Figure 1c).

Understory vegetation can be an important part of the stand productivity and become a competitor with trees for growth resources, similarly to previous studies in plantations in sub-tropical China [28], understory vegetation may contribute up to $40 \%$ of total annual stand NPP within the first 10 years of afforestation, when the trees were small and light could reach the forest floor. In most situations, the contribution of understory vegetation to annual NPP dropped to less than $10 \%$ after year 15 in the rich and medium sites and after 40-50 years in the poor sites. Taking the 100-year period as a whole, in rich and medium sites, the understory vegetation added only $1 \%-3 \%$ to the total accumulated NPP, while in poor sites, it could account for $8 \%-10 \%$ (Figure 1).

Our results are opposed to the theory of [15] that in low-fertility sites where mixed stands reach their maximum over-yield compared to pure stands. Kelty's generalized hypothesis has also not been supported by results from other tropical forests [35,51]. Instead, our results indicate that the more recent hypothesis by [17], relating differences in the productivity of mixed stands compared to monocultures as dependent on the differentiation of the fundamental niche of the species used in the admixtures. In fact, our estimated yield surpluses (positive and negative) are generally small, especially compared to reports from other sub-tropical and tropical mixed forests $[15,18,52,53]$. One reason for such a difference is that in the cited works, N-fixing species were used in the mixtures, which was not the case in our simulations.

Another reason for the lack of an important over-yielding effect at the stand level in our simulations is the effect of a productivity increase in one species being compensated by a productivity decrease in 
the companion species (Figure 2). Neutral mixture effects or reduced productivity largely include species mixtures comprising light-demanding species [54] or mixtures with permanent asymmetrical competition. This is similar to our simulated stands, composed of two light-demanding species [55] with very different life spans.

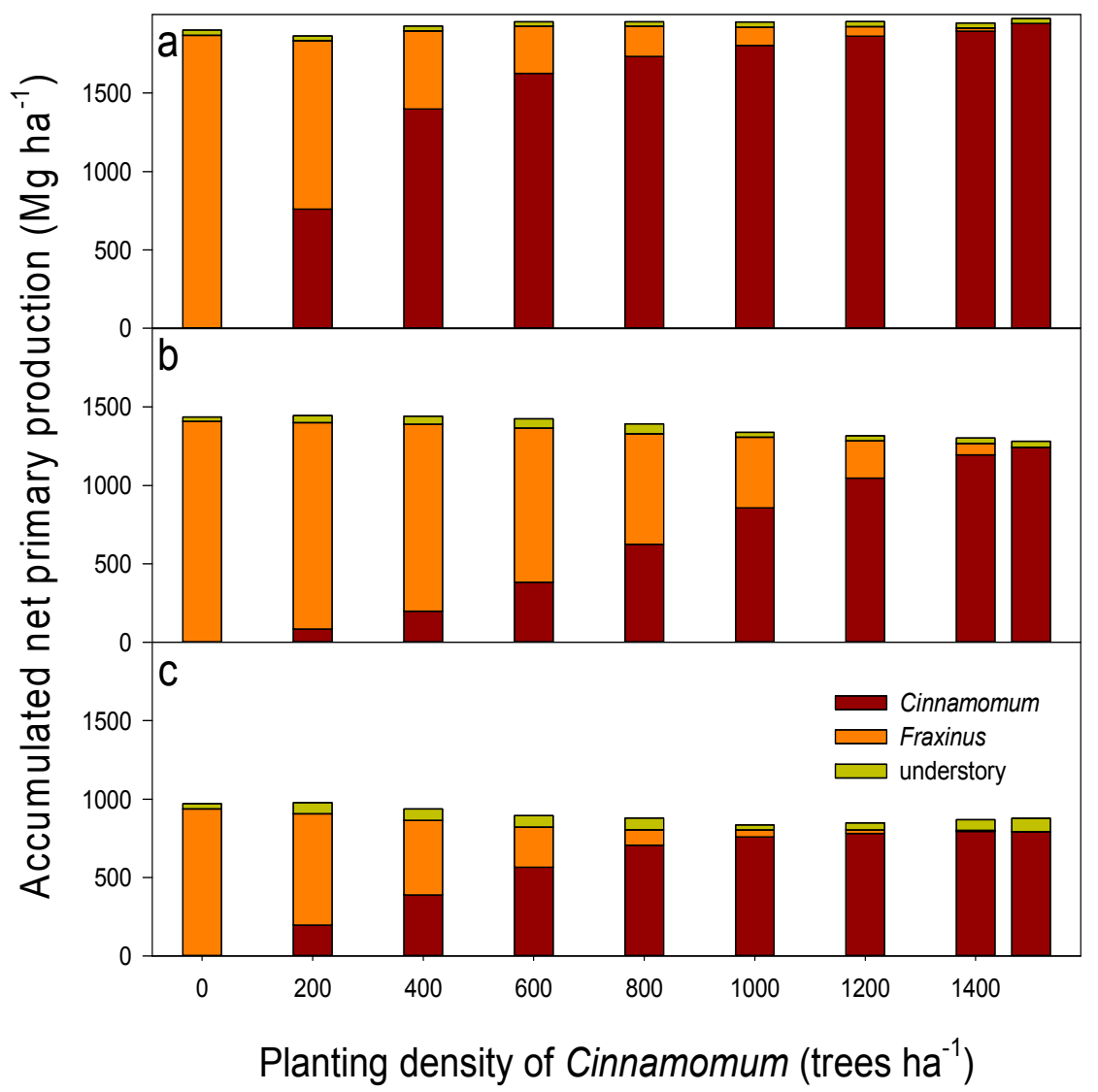

Figure 1. Accumulated stand (trees + understory) net primary production at final rotation (100 years) time for the sites of (a) rich; (b) medium and (c) poor quality.

To have a detailed view of the relative contribution of the two tree species on total aboveground biomass, snapshots of the stands at year 50 are shown in Figure 2. Camphor laurel benefitted from the mixing with Himalayan ash when growing in any site quality, whereas Himalayan ash only benefited from the presence of camphor laurel for medium sites. The relative yield of Cinnamomum camphora in the 200-1300 ha $\mathrm{ha}^{-1}$ mixture of Cinnamomum camphora-Fraxinus griffithii was $189 \%$ and $157 \%$ for the rich and poor sites, respectively. This gradually decreased with increasing density of Cinnamomum camphora in the mixture. In contrast, the yield of Himalayan ash woody biomass was suppressed by the co-existence with camphor laurel at both rich and poor sites.

The pattern of inter-specific competition reversed in the medium sites. Fraxinus griffithii had $4 \%-10 \%$ more yield of aboveground woody tissue than that calculated from the pure stand. The relative yields of Cinnamomum camphora were on the contrary all lower than $100 \%$ (Figure $2 \mathrm{~b}$ ). In this site condition with medium quality of resources, the yield surplus of mixed plantations was contributed by Fraxinus griffithii. 

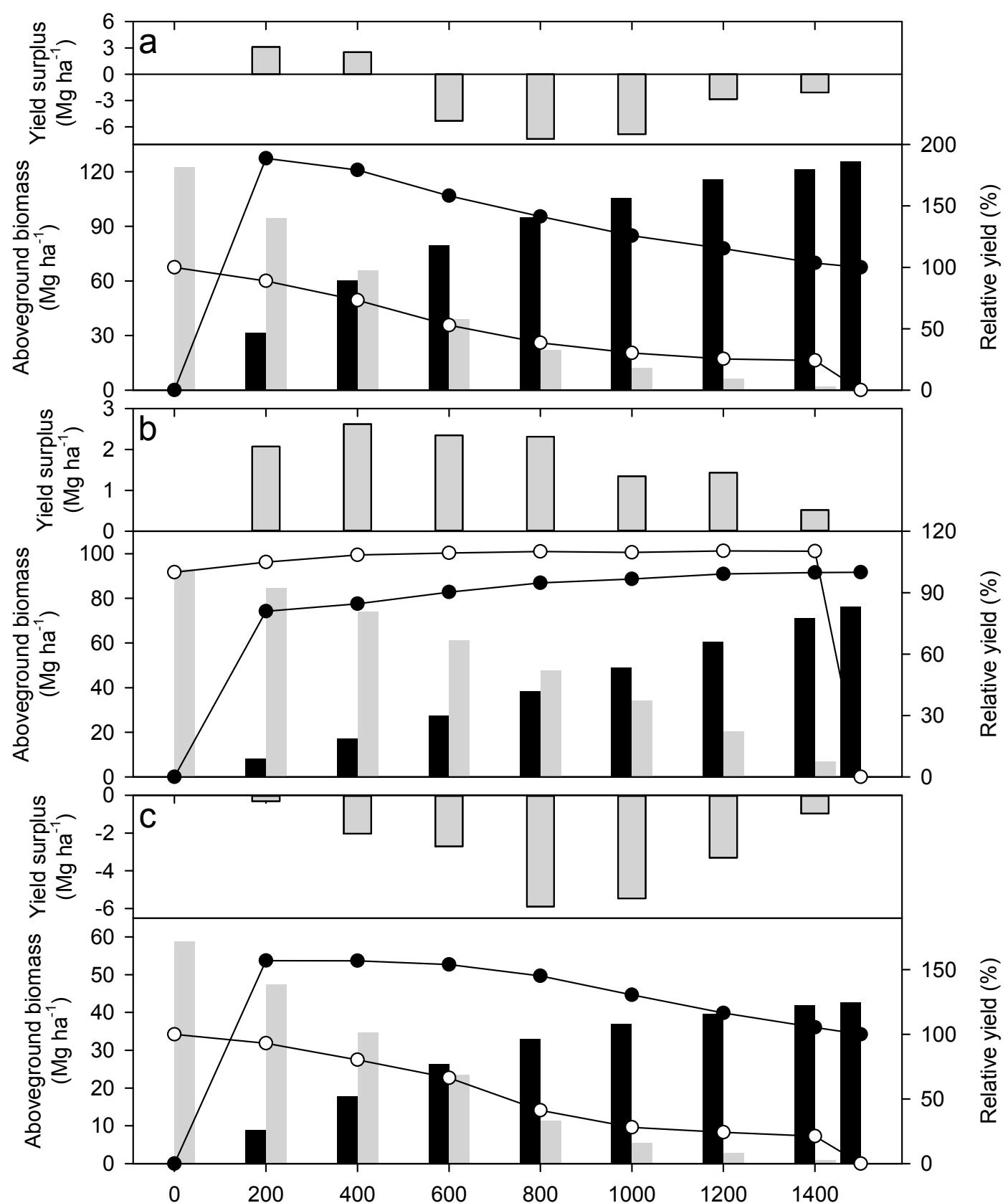

Planting density of Cinnamomum (trees ha ${ }^{-1}$ )

Figure 2. Aboveground woody tissue $($ stem + branch) biomass of the trees for (a) rich; (b) medium and (c) poor sites in year 50 of the plantation. The upper part of each panel represents the yield surplus, while the lower part demonstrates the respective biomass of Cinnamomum camphora (dark bar) and Fraxinus griffithii (grey bar). The filled and open circle is the relative yield of Cinnamomum camphora and Fraxinus griffithii, respectively, referring to their monocultures.

Differences in tree architecture could explain this competition/facilitation pattern. Camphor laurel is a moderate- to fast-growing, long-lived species, reaching up to $50 \mathrm{~m}$ tall in the best site conditions [56]. On the contrary, Himalayan ash is a typical fast-growing, short-lived species not passing $10 \mathrm{~m}$ tall. Both species are highly light demanding [55] and have been reported as invasive 
species, particularly camphor laurel trees in Australia [57]. In addition to canopy height, Himalayan ash is more $\mathrm{N}$ demanding than camphor laurel, particularly given the high leaf $\mathrm{N}$ content, typical from Fraxinus species [58,59]. Therefore, Himalayan ash would be unable to survive under the camphor laurel canopy, and in sites with low nutrient availability, camphor trees would be favored against ash. Such differences indicate that the realized niches of both species differ both in space (with camphor laurel being larger, both in canopy height and root architecture), but also in time. Through the influence of the two species on each other (e.g., overshadowing, suppression in the root space), the width of the fundamental niche of each species may be restricted to a narrower, realized niche [17]. This reduction in the realized niche probably occurs in the rich site when the initial height of Himalayan ash is very inferior to camphor laurel.

Increased productivity from aboveground niche differentiation is expected, especially on fertile sites (good site quality), because better light conditions are the most important factor affecting growth. The relatively limited access of Himalayan ash to light under the camphor laurel canopy can lead to a permanent decline and ultimately to the elimination of a species in the stand. In practice, this creates an asymmetrical competitiveness that could make the mixture unstable [60]. In theory, asymmetrical competition can be regulated through forest management, promoting one species or inhibiting the other, depending on the desired stand composition [61]. One example of such management techniques is the so-called "two-pass system", suggested for managing mixed sub-boreal forest in North America [62].

Camphor laurel growth in mixed stands seems to improve as a result of Himalayan ash working as a "nutrient retention system", which reduces leaching losses from the system during the first years of each rotation, combining its fast juvenile growth with higher nutrient demands than camphor laurel. This situation benefits camphor laurels as it reduces $\mathrm{N}$ losses from the ecosystem, particularly at the beginning of the rotation when camphor laurels are small and do not capture and use most of the available N. Later, when ash declines and leaf and woody litter decompose, such nutrients are released and can be used by camphor laurel trees. Similar mechanisms to reduce nutrient losses from the ecosystems have been reported before for Chinese sub-tropical forests [28,31-33]. In addition, stand litter production increases in mixed forests, a phenomenon reported before [63]. Higher litter loads combined with slower decomposition from ash leaves than camphor laurel leaves also contributes to higher accumulation of nutrients in soil.

On sites where soil resources are limiting for growth, niche differentiation in the soil space, such as a combination of deep and shallow rooting trees, is advantageous. Although the current theory in over-yielding effects in mixed stands states that the less favorable and less fertile the soil is (the more eccentric the location of the given site in the niche), the more likely a species mixture will result in a production increase [17], our results indicate that poor sites will also have a negative yield surplus. This could be a consequence of the absolute over-yielding effect, and it might be much smaller in poor sites than under light-limiting conditions (rich sites), since on sites with limiting soil resources, primarily a greater investment in root mass is needed to reach additional soil resources.

In addition, the presence of understory, which could be taking a significant amount of nutrients during the early part of the rotation, effectively prevents Himalayan ash from using its fast-growing potential when its density is low. Such strong competition between understory and fast-growing species in the subtropical region of China has been described [28]. On the other hand, that the two species are able to coexist in stands of medium quality may indicate that their niches are differentiated 
effectively by adjusting their competitiveness to the site conditions (temporally and spatially) [17]. As a consequence, the mixture effect not only varies with site quality and camphor/ash tree density ratios, but also through time (Figure 3).

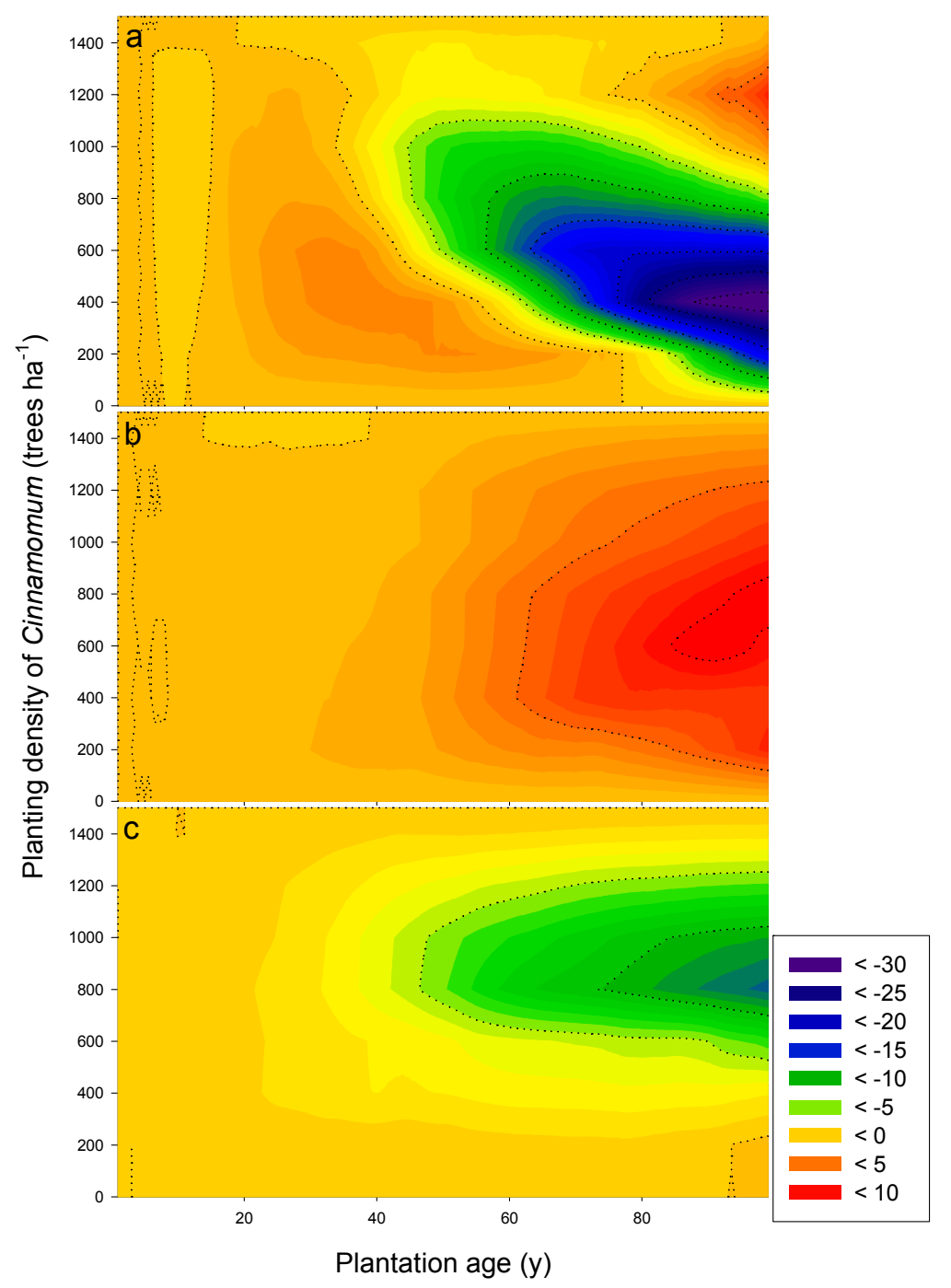

Figure 3. Yield surplus $\left(\mathrm{Mg} \mathrm{ha}^{-1}\right)$ (see the definition in the text) of the mixed stands through the 100-year plantation age in (a) rich; (b) medium and (c) poor sites. Y-axes of the contour plots represent different combinations of Cinnamomum and Fraxinus (zero means pure Fraxinus stands and 1,500 pure Cinnamomum stands). X-axes represent stand age up to 100 years. The colors towards the orange end of the spectrum indicate a higher yield surplus of the mixed stands.

Under rich site quality, two main regions with a positive yield surplus could be observed in the two-dimensional plane of Figure 3a: one is the mixed stands with 1000 to $1400 \mathrm{ha}^{-1}$ of Cinnamomum camphora for the period from year 80 to the end of the rotation; another is the lower left triangle of the plane with the peak values being concentrated in the mixed stand with $400 \mathrm{ha}^{-1}$ of Cinnamomum camphora growing to between 30 and 40 years old. These results indicate that under low camphor laurel densities, competition pressure from camphor laurel on Himalayan ash is reduced, and therefore, ash can take advantage of the high fertility and faster nutrient cycling created by the 
presence of camphor laurel leaf litter, which decompose faster. This allows ash trees to use the growing space [64] not used by camphor laurel trees. However, such a window of opportunity quickly disappears as camphor laurel trees overgrow ash trees and start shadowing them out. Such a capacity of camphor laurel to suppress and shadow out other tree species has been reported before in tropical forests in Australia, where selective killing of dominant camphor laurel trees is used to release the native woody species undergrowth [57].

Later in the rotation, the large negative-value area in Figure $3 \mathrm{a}$ represents the mixed stands providing less yield of woody biomass than the linear combination of monocultures of both species. The greatest biomass reduction happened in the old 400-1100 ha $\mathrm{h}^{-1}$ mixed stand. These results reflect two phenomena: (i) most of the loss of the biomass earlier produced from ash trees has become litterfall and decomposed; and (ii) the opportunity cost of planting low camphor laurel densities, which even with high resource availability are not able to be as productive as the fully-stocked monocultures.

In the case of poor site quality, none of the mixed planting sites yield more harvestable wood than the pure stands did (Figure 3c). All mixed stands have very similar productivity to pure stands until mid-rotation (45-55 years). After that time, the mixtures closer to a 1:1 camphor/ash density ratio start to lose productivity compared to monocultures. This result points to a competitive pressure of camphor laurel on Himalayan ash, in which the increased productivity of the camphor laurels by the presence of ash trees does not compensate for the reduced productivity of ash trees. This effect is increased as time advances until the end of the rotation.

In contrast, when growing on medium-quality sites, almost all mixing scenarios produced surplus biomass, although the amount of surplus biomass was only marginal throughout the whole period of plantation (Figure $3 \mathrm{~b}$ ). The higher surplus production among the different mixing scenarios generally occurred in the mixture of an equal number of Cinnamomum camphora and Fraxinus griffithii. At the end of the 100-year rotation, the highest yield surplus was about $11 \mathrm{Mg} \mathrm{ha}^{-1}$. This estimated over-yield is a consequence of the differentiation of the time of maximum productivity for each species. By having moderate nutrient availability, fast-growing Himalayan ash can produce significant biomass in the first half of the rotation, whereas camphor laurel's slower growth peaks after the ash trees have passed their maximum productivity time. As a consequence, maximum stand productivity is maintained longer than in any monoculture.

\subsection{Long-Term Sustainability of the Productivity in Mixed Camphor Laurel-Himalayan Ash Plantations}

From a site quality (nutritional) point of view, sustainability can be defined as the capacity of a given management regime to sustain productivity over time [65]. Soil is the support of all vegetation growth, and therefore, a criterion for maintaining sustainability is keeping soil productivity stable in the long run [34], which then can be measured with two indicators: the amount of soil organic matter and available $\mathrm{N}[13,66]$. Both variables are essential components of ecosystem resiliency $[7,8]$. Therefore, it is important to estimate in the medium- to long-term not only productivity, but also soil organic matter and $\mathrm{N}$ availability in new mixtures of camphor laurel-Himalayan ash.

In our simulations, a common temporal pattern of the soil organic matter (SOM) pool could be seen in all kinds of plantations (Figure 4). The storage first decreased due to a higher decomposition rate 
than the rate of litter input. Such reductions in SOM after reforesting former farmlands have been reported before [67]. This trend extended to about years 20 to 30 and the SOM storage started to increase with plantation age. At the year of harvest, a sharp rise in the SOM pool was due to the addition of slash from the overstory: $10 \%$ of tree leaves, $10 \%$ of branches and $5 \%$ of the tree stem biomass were left on site after simulating harvesting.

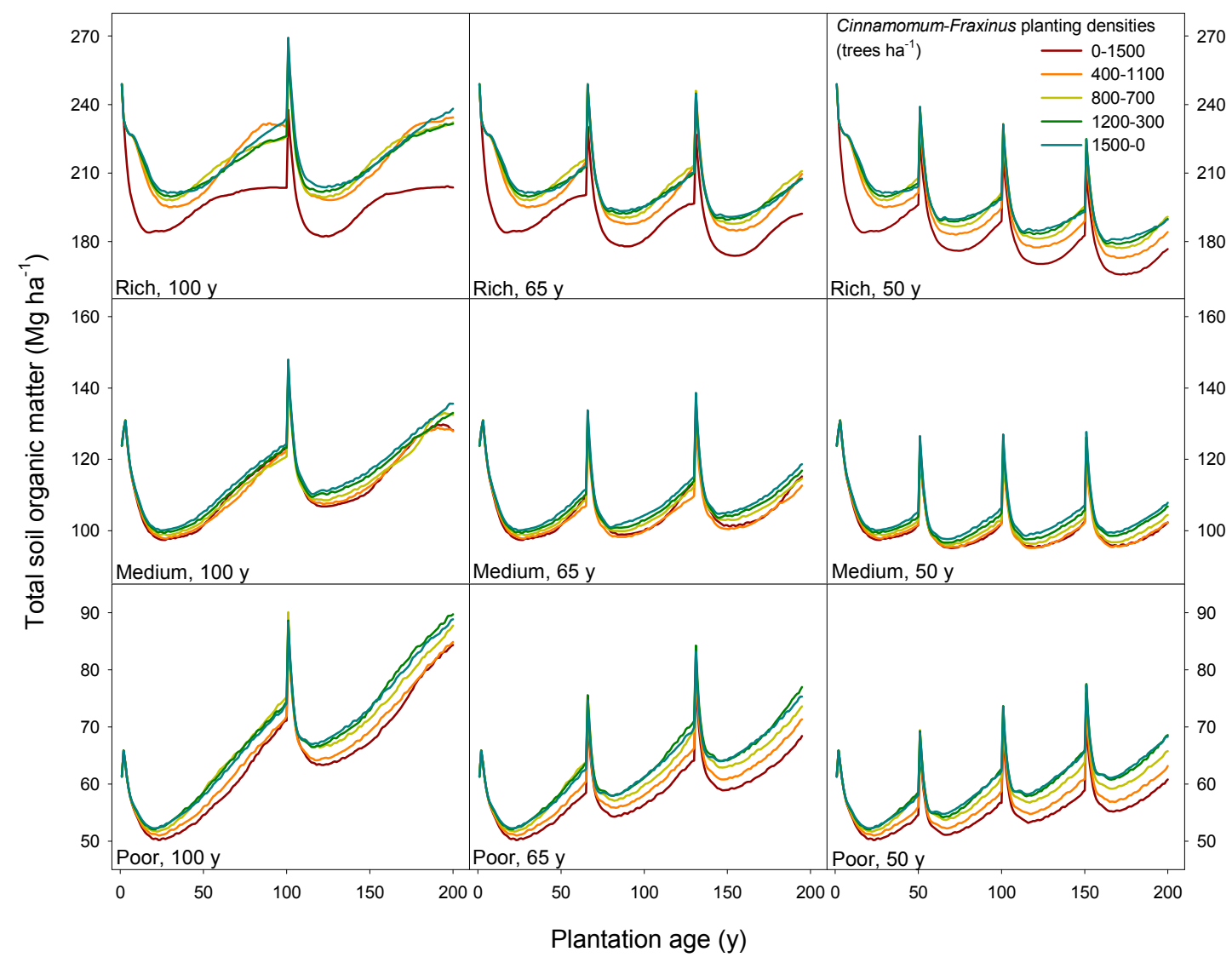

Figure 4. Total soil organic matter (litter + humus) for three different sites, three rotation schemes and five different combinations of Cinnamomum camphora and Fraxinus griffithii planting densities (the ratio of the tree density of Cinnamomum to Fraxinus ranging from 0-1500, i.e., pure Fraxinus, to 1500-0, i.e., pure Cinnamomum).

In the total period of 200 years, the four consecutive 50-year rotations led to a lower value of SOM at the end of the period than the repetition of 100-year or 65-year rotations. In the rich site, all rotation schemes resulted in a reduction of SOM relative to the initial values prior to afforestation. On the contrary, the afforestation in the poor site helped to enhance the SOM pool, which was rather drastic in the two consecutive 100-year rotation sites with an increase up to $46 \%$ of the initial value (for the mixing scheme of 1200 camphor laurel-300 Himalayan ash trees $\mathrm{ha}^{-1}$ ). This buildup of SOM in poor sites under mixed stands has been reported before for sub-boreal and temperate forests [13].

Stands of different combinations of camphor laurel and Himalayan ash planting densities led to different final values of SOM. In the rich sites, the monoculture of Fraxinus griffithii depleted SOM to the lowest level compared to other mixing scenarios. As long as Cinnamomum camphora was planted with Fraxinus griffithii, the SOM pool could be significantly raised, and different combinations 
seemed to be of minor effect on SOM, a consequence of the increased inputs to SOM by litter fall achieved in mixed forests, a phenomenon reported before [63]. For the medium and poor sites, the uniqueness of Fraxinus griffithii pure stand disappeared: the SOM level from all mixing scenarios remained similar, although a clear trend of increasing SOM by increasing Cinnamomum camphora density could be found. Such results also show the potential resiliency of these mixed forests in the long term, even when a program of frequent disturbances of anthropic origin is imposed on them.

Besides SOM, total available nitrogen in the soil is another key state factor that warrants the sustainability of an ecosystem. Soil available nitrogen changed by different mixing combinations and rotation scenarios under different site qualities (Figure 5). Camphor laurel demonstrated high efficiency of $\mathrm{N}$ uptake, which, combined with its higher productivity, resulted in a strong reduction of soil-available nitrogen. The monoculture of Himalayan ash largely increased the soil-available nitrogen pool in the rich sites, especially for the two consecutive 100 -year rotations scheme, thus enhancing the mixed forest resiliency against other disturbances. At these sited, Himalayan ash trees reach their maximum productivity peak early in the rotation (before year 30), and then, their $\mathrm{N}$ uptake demand quickly decreases.

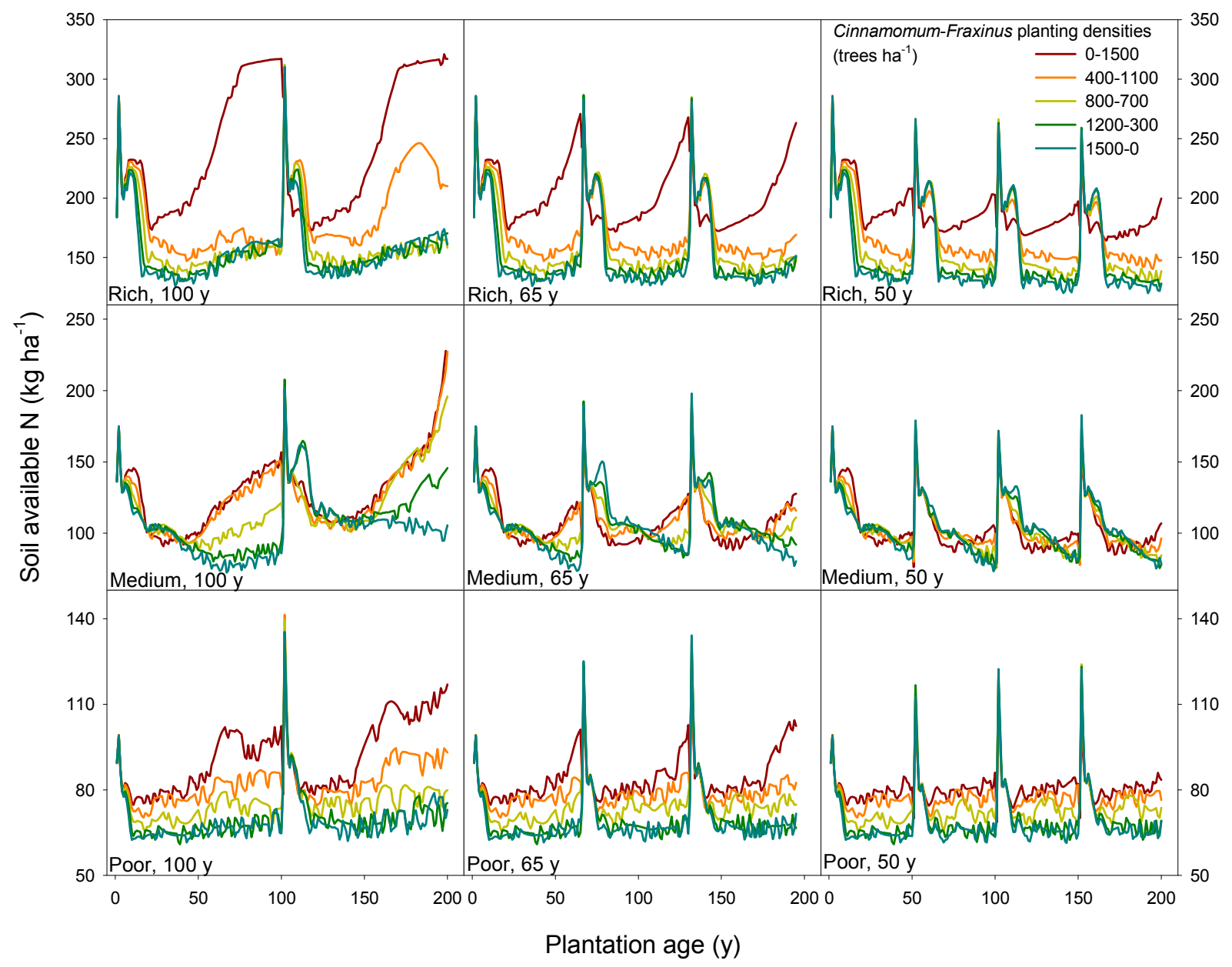

Figure 5. Soil-available N (see Section 2.2 for a definition) for three different sites, three rotation schemes and five different combinations of Cinnamomum camphora and Fraxinus griffithii planting densities (ratio of tree density of Cinnamomum to Fraxinus ranging from 0-1500, i.e., pure Fraxinus, to 1500-0, i.e., pure Cinnamomum). 
Similar to the pattern of SOM, the more frequent harvest and re-planting of any of both species will decrease the level of soil-available $\mathrm{N}$ in the long term, as this nutrient is exported from the site, as found for other tropical and temperate forests before $[28,30,66,68]$. The exception is the sites with a higher proportion of camphor laurel trees in the mixed stands, in which the soil-available $\mathrm{N}$ also decreased to a very low level in the 100-year rotation scheme. Such results support the theory that mixed stands can be more efficient in using soil nutrients [63].

\subsection{Model Limitations and Further Work}

The predicted biomass values for pure stands are inside the observed biomass range in the field. However, as in any modeling exercise, there are sources of uncertainty. First, data on forest condition prior to agricultural expansion into the plain areas is basically non-existent. Here, we have assumed that at that point, forests could be in an almost steady state as a result of non-human intervention. However, these forests may have had some low-intensity management (i.e., fire wood collection, sporadic selective logging, etc.) for at least since the arrival of the first foreign colonist 400 years ago. However, just by collecting firewood, the amount of coarse woody debris present had likely been lower than the one estimated here, and therefore, the initial SOM pools could have been lower than the one estimated here [69].

We should also point out that although being an ecosystem-level model, FORECAST does not currently include simulation of ecosystem features, such as hydrology or microclimate, which can affect nutrient cycles and are themselves affected by changing management. However, given the high rainfall levels the whole year round in Hualien, no moisture deficit is expected that could significantly influence tree growth, and the model's lack of explicitly accounting for water flows should then be of minor consequence to its estimations. Furthermore, disturbances, such as pest outbreaks and especially typhoons, have not been simulated to reduce the complexity when interpreting the simulation results, but there is no doubt that they would be present in mixed stands at these sites. However, mixed stands are also proposed as a suitable management option, as they reduce pest and wind damage by breaking the homogeneity of monocultures [50].

While more validation work needs to be conducted in a range of different mixed stand types and management interventions as datasets become available, the analysis described herein provides a first approach for using this model as a decision-support tool in these ecosystem types under prevailing climatic conditions. In the face of climate change predictions, further validation work will be needed for all forest growth models to assess their ability to adapt to this change in the environmental setting for ecosystem function [34]. Finally, it is important to know how the uncertainty related to calibration values is transmitted to output variables. Studies on the sensitivity of FORECAST [20,26,28,70] indicate that the model is more sensitive to the uncertainty of the calibration parameters when complex site preparation or management practices are applied.

\section{Conclusions and Management Implications}

All things considered, our quantitative estimations should be taken with caution, although the productivity patterns are likely representative of the potential biomass generated in mixed afforestation plantations on former farmlands in Eastern Taiwan. With this constraint in mind, we consider that our 
work has been useful to establish a first approach for the magnitude of the stand-level productivity changes in camphor laurel-Himalayan ash plantations in former farmlands and the type of tradeoffs that forest managers face when trying to maximize both production and resiliency. Our research also shows the viability of using ecosystem-level models as tools for research and management guidance in the absence of field data and trial plots.

Mixed stands of camphor laurel and Himalayan stands have not been planted before, likely due to the difficulty of managing a mixture or early- and late-successional species. However, in abandoned farmlands, mixed plantations could be a viable option to increase ecological productivity and resilience, although the composition of the mixed stand will depend on site quality. In poor sites (likely caused by shallow or eroded soils), planting Himalayan ash seems the most viable option to maximize plant productivity and organic matter inputs to soil. Medium rotation lengths (50 years) would still allow for accumulating soil organic matter and improving site quality, although long rotations (100 years) seem to be the most adequate for this purpose. They also seem more adequate for managing the ecosystem inside its resiliency limits.

In medium sites, a mixed stand with 2:1 to 1:1 camphor laurel- Himalayan ash density ratios would maximize stand productivity and, at the same time, increase biodiversity and niche differentiation for wildlife. Medium (50 years) rotation lengths should be avoided due to the uncertainty on their capacity to keep soil organic matter and its associated site quality in the long term. Managing a mixed stand would require careful planning and understanding the timing of each species' growth. In addition to traditional thinning or intermediate cutting, other options to explore could be using a two-pass system, where Himalayan ash is removed from the sites before it is shadowed out or, alternatively, extracting the most dominant camphor laurel trees to extend the period in which available light is adequate for Himalayan ash.

In rich, high-fertility sites, pure camphor laurel plantations (or with a small proportion of Himalayan ash) would maximize ecosystem productivity, but long rotation lengths (100 years) should be used to ensure the maintenance of the soil fertility.

\section{Supplementary Materials}

Supplementary materials can be accessed at: http://www.mdpi.com/2071-1050/7/4/3801/s1.

\section{Acknowledgments}

Yueh-Hsin Lo was funded by the Spanish Ministry of Economy and Competitiveness (Ref. AGL2012-33465). Juan A. Blanco was funded through a "Ramón y Cajal" contract (Ref. RYC-2011-08082) and a Marie Curie Action (Ref. CIG-2012-326718-ECOPYREN3). Shih-Chieh Chang was given a grant by the Ministry of Science and Technology (Ref. NSC 102-2621-M-259-005)

\section{Author Contributions}

Each author contributed equally to this work. Chia-Hsin $\mathrm{Wu}$ and Yueh-Hsin Lo carried out the simulations. Juan A. Blanco calibrated the FORECAST model. Shih-Chieh Chang designed the 
research concept. All authors contributed to analyzing and discussing the results. All authors read and approved the manuscript.

\section{Conflicts of Interest}

The authors declare no conflict of interest.

\section{References}

1. Rudel, T.K.; Perez-Lugo, M.; Zichal, H. When fields revert to forest: Development and spontaneous reforestation in post-war Puerto Rico. Prof. Geogr. 2000, 52, 386-397.

2. Lambin, E.F.; Meyfroidt, P. Global land use change, economic globalization, and the looming land scarcity. Proc. Natl. Acad. Sci. USA 2011, 108, 3465-3472.

3. Meyer, W.B.; Turner, B.L. Human population growth and global land-use/cover change. Annu. Rev. Ecol. Syst. 1992, 23, 39-61.

4. FOREST EUROPE; UNECE; FAO. State of Europe's Forests 2011. Status and Trends in Sustainable Forest Management in Europe; Ministerial Conference on the Protection of Forests in Europe: Aas, Norway, 2011; p. 337.

5. FAO. State of the World's Forests 2014; Food and Agriculture Organization of the United Nations: Rome, Italy, 2014; p. 119.

6. Alston, M. Who is down on the farm? Social aspects of Australian agriculture in the 21 st century. Agr. Hum. Values 2004, 21, 37-46.

7. Lin, K.-C.; Liu, W.-Y. An empirical study of afforestation policy in Taiwan. Socioecon. Law Inst. Rev. 2007, 40, 175-211. (In Chinese)

8. Lo, K.-A. Agricultural landowners' participation in the plain landscape afforestation program (PLAP): A case study in Taitung County, Taiwan. Q. J. For. Res. 2005, 27, 17-30. (In Chinese)

9. Kimmins, J.P.; Blanco, J.A.; Seely, B.; Welham, C.; Scoullar, K. Forecasting Forest Futures: A Hybrid Modelling Approach to the Assessment of Sustainability of Forest Ecosystems and Their Values; Earthscan: London, UK, 2010; p. 281.

10. Messier, C.; Puettmann, K.J.; Coates, K.D. Managing forests as complex adaptive systems: Building resilience to the challenge of global change. In The Earthscan Forest Library; Routledge: London, UK, 2013; p. 368.

11. Herbert, D.A.; Fownes, J.H.; Vitousek, P.M. Hurricane damage to a Hawaiian forest: Nutrient supply rate affects resistance and resilience. Ecology 1999, 80, 908-920.

12. Chapin, F.S.; McGuire, A.D.; Ruess, R.W.; Hollingsworth, T.N.; Mack, M.C.; Johnstone, J.F.; Kasischke, E.S.; Euskirchen, E.S.; Jones, J.B.; Jorgenson, M.T.; et al. Resilience of Alaska's boreal forest to climatic change. Can. J. For. Res. 2010, 40, 1360-1370.

13. Blanco, J.A.; Dubois, D.; Littlejohn, D.; Flanders, D.N.; Robinson, P.; Moshofsky, M.; Welham, C. Soil organic matter: A sustainability indicator for wildfire control and bioenergy production in the urban/forest interface. Soil Sci. Soc. Am. J. 2014, doi:10.2136/sssaj2013.06.0214.

14. Dymond, C.C.; Tedder, S.; Spittlehouse, D.L.; Raymer, B.; Hopkins, K.; McCallion, K.; Sandland, J. Diversifying managed forests to increase resilience. Can. J. For. Res. 2014, 44, $1196-1205$. 
15. Kelty, M.J. Comparative productivity of monocultures and mixed-species stands. In The Ecology and Silviculture of Mixed-Species Forests; Kelty, M.J., Larson, B.C., Oliver, C.D., Eds.; Springer: Berlin, Germany, 1992; pp. 125-141.

16. Chomel, M.; DesRochers, A.; Baldy, V.; Larchevêque, M.; Gauquelin, T. Non-additive effects of mixing hybrid poplar and white spruce on aboveground and soil carbon storage in boreal plantations. For. Ecol. Manag. 2014, 328, 292-299.

17. Pretzsch, H. Forest Dynamics, Growth, and Yield: From Measurement to Model; Springer: Berlin, Germany, 2009; p. 664.

18. Forrester, D.I.; Bauhus, J.; Cowie, A.L.; Vanclay, J.K. Mixed-species plantations of Eucalyptus with nitrogen-fixing trees: A review. For. Ecol. Manag. 2006, 233, 211-230.

19. Lo, Y.-H.; Blanco, J.A.; Kimmins, J.P.; Seely, B.; Welham, C. Linking climate change and forest ecophysiology to project future trends in tree growth: A review of forest models. In Climate Change-Research and Technology for Adaptation and Mitigation; Blanco, J.A., Kheradmand, H., Eds.; InTech: Rijeka, Croatia, 2011; pp. 63-86.

20. Kimmins, J.P.; Mailly, D.; Seely, B. Modelling forest ecosystem net primary production: The hybrid simulation approach used in FORECAST. Ecol. Model 1999, 122, 195-224.

21. Sachs, D.; Sollins, P. Potential effects of management practices on nitrogen nutrition and long-term productivity of western hemlock stands. For. Ecol. Manag. 1986, 17, 25-36.

22. Wang, J.R.; Comeau, P.; Kimmins, J.P. Simulation of mixedwood management of aspen and white spruce in northeastern British Columbia. Water Air Soil Pollut. 1995, 82, 171-178.

23. Morris, D.M.; Kimmins, J.P.; Duckert, D.R. The use of soil organic matter as a criterion of the relative sustainability of forest management alternatives: A modelling approach using FORECAST. For. Ecol. Manag. 1997, 94, 61-78.

24. Wei, X.; Liu, W.; Waterhouse, J.; Armleder, M. Simulations on impacts of different management strategies on long-term site productivity in lodgepole pine forests of the central interior of British Columbia. For. Ecol. Manag. 2000, 133, 217-229.

25. Wei, X.; Kimmins, J.P.; Zhou, G. Disturbances and the sustainability of long-term site productivity in lodgepole pine forests in the central interior of British Columbia-An ecosystem modeling approach. Ecol. Model. 2003, 164, 239-256.

26. Blanco, J.A.; Seely, B.; Welham, C.; Kimmins, J.P.; Seebacher, T.M. Testing the performance of a forest ecosystem model (FORECAST) against 29 years of field data in a Pseudotsuga menziesii plantation. Can. J. For. Res. 2007, 37, 1808-1820.

27. Seely, B.; Welham, C.; Blanco, J.A. Towards the application of soil organic matter as an indicator of forest ecosystem productivity: Deriving thresholds, developing monitoring systems, and evaluating practices. Ecol. Indic. 2010, 10, 999-1008.

28. Bi, J.; Blanco, J.A.; Seely, B.; Kimmins, J.P.; Ding, Y.; Welham, C. Yield decline in Chinese-fir plantations: A simulation investigation with implications for model complexity. Can. J. For. Res. 2007, 37, 1615-1630.

29. Blanco, J.A.; González, E. Exploring the sustainability of current management prescriptions for Pinus caribaea plantations in Cuba: A modelling approach. J. Trop. For. Sci. 2010, 22, 139-154.

30. Blanco, J.A.; González, E. The legacy of forest management in tropical forests: Analysis of its long-term influence with ecosystem models. For. Syst. 2010, 19, 249-262. 
31. Xin, Z.H.; Jiang, H.; Jie, C.Y.; Wei, X.H.; Blanco, J.; Zhou, G.M. Simulated nitrogen dynamics for a Cunninghamia lanceolata plantation with selected rotation ages. J. Zhejiang Agric. For. Univ. 2011, 28, 855-862.

32. Blanco, J.A.; Wei, X.; Jiang, H.; Jie, C.-Y.; Xin, Z.-H. Impacts of enhanced nitrogen deposition and soil acidification on biomass production and nitrogen leaching in Chinese fir plantations. Can. J. For. Res. 2012, 42, 437-450.

33. Wei, X.H.; Blanco, J.A.; Jiang, H.; Kimmins, J.P. Effects of nitrogen deposition on carbon sequestration in Chinese fir forest ecosystems. Sci. Total Environ. 2012, 416, 351-361.

34. Seely, B.; Hawkins, C.; Blanco, J.; Welham, C.; Kimmins, J. Evaluation of a mechanistic approach to mixedwood modelling. For. Chron. 2008, 84, 181-193.

35. Wei, X.H.; Blanco, J.A. Significant increase in ecosystem C can be achieved with sustainable forest management in subtropical plantation forests. PLoS One 2014, 9, e89688.

36. Liao, J.C. Lauraceae. In Flora of Taiwan, 2nd ed.; Editorial Committee of the Flora of Taiwan, Ed.; Department of Botany, Nation Taiwan University: Taipei, Taiwan, 1996; p. 481.

37. Chen, Z.H.; Wu, B.; Li, J.Y.; Zhao, J.G.; Zhou, X.Y.; Zhang, Y.K. Germination of the seeds and growth of seedlings of Cinnamomum camphora (L.) Presl. Plant Species Biol. 2004, 19, 55-58.

38. Miyawaki, A.; Fujiwara, K.; Hada, Y.; Itoh, S.; Miyata, I.; Miyoshi, N.; Murakami, Y.; Nakagoshi, N.; Nakanishi, H.; Nakamura, Y. Vegetation of Japan. Vol. 4. Chugoku; Shibundo: Tokyo, Japan, 1983; p. 540.

39. Pakenham, T. Remarkable Trees of the World; Weidenfeld \& Nicolson: London, UK, 2002.

40. Penman, J.; Gytarsky, M.; Hiraishi, T.; Krug, T.; Kruger, D.; Pipatti, R.; Buendia, L.; Miwa, K.; Ngara, T.; Tanabe, K.; et al. Good Practice Guidance for Land Use, Land-Use Change and Forestry; IPCC National Greenhouse Gas Inventories Programme and Institute for Global Environmental Strategies: Kanagawa, Japan, 2003.

41. Landsberg, J. Modelling forest ecosystems: State of the art, challenges, and future directions. Can. J. For. Res. 2003, 33, 385-397.

42. Kimmins, J.P. Scientific Foundations for the Simulation of Ecosystem Function and Management in FORCYTE-11; Information Report NOR-X-328; Forestry Canada: Edmonton, AB, Canada, 1993; p. 88

43. Yao, Y.J.; Kang, W.X.; Tian, D.L. Study of the biomass and productivity of Cinnamomum camphora plantation. J. Cent. South For. Univ. 2003, 23, 1-5. (In Chinese)

44. Lee, H.-T.; Feng, F.-L. A forest carbon sequestration inventory system: An example of camphor trees in Taiwan. Taiwan J. For. Sci. 2008, 23 (Supplement), S11-S22. (In Chinese)

45. Lei, P.F.; Xiang, W.H.; Tian, D.L.; Fang, X. Carbon storage and distribution in Cinnamomum camphor plantation. Chin. J. Ecol. 2004, 23, 25-30. (In Chinese)

46. Lin, K.C.; Duh, C.T.; Huang, C.M. Estimate of carbon storage and sequestration of Fraxinus griffithii plantations in Taiwan. Q. J. Chin. For. 2010, 43, 261-276. (In Chinese)

47. Welham, C.; van Rees, K.; Seely, B.; Kimmins, H. Projected long-term productivity in Saskatchewan hybrid poplar plantations: Weed competition and fertilizer effects. Can. J. For. Res. 2007, 37, 356-370. 
48. Castrillón, Y.; Blanco, J.A.; Primicia, I.; Ansó, M.; Imbert, J.B.; Castillo, F.J. Evaluation of the ecological model FORECAST to simulate litter production in pine stands in the Pyrenees. In Proceedings of the 11th Congress of the AEET-Invitation to Ecology: Strengthening links with Society, Pamplona, Spain, 6-10 May 2013.

49. Jie, C.; Jiang, H.; Zhou, G.; Wei, X.; Blanco, J.; Jiang, Z.; Xin, Z. Simulating the carbon storage of spruce forests based on the FORECAST model and remotely sensed data. In Proceedings of the Geoinformatics, 2011 19th International Conference on Geoinformatics, Shanghai, China, 24-26 June 2011; IEEE: Piscateway, NJ, USA, 2011; pp. 1-6.

50. Amoroso, M.M.; Turnblom, E.C. Comparing productivity of pure and mixed Douglas-fir and western hemlock plantations in the Pacific Northwest. Can. J. For. Res. 2006, 36, 1484-1496.

51. Lugo, A.E. Comparison of tropical tree plantations with secondary forests of similar age. Ecol. Monogr. 1992, 62, 1-41.

52. DeBell, D.S.; Whitesell, C.D.; Schubert, T.H. Using $\mathrm{N}_{2}$-fixing Albizia to increase growth of Eucalyptus plantations in Hawaii. For. Sci. 1989, 35, 64-75.

53. Forrester, D.I.; Bauhus, J.; Cowie, A.L.; Mitchell, P.A.; Brockwell, J. Productivity of three young mixed-species plantations containing $\mathrm{N}_{2}$-fixing Acacia and non- $\mathrm{N}_{2}$-fixing Eucalyptus and Pinus trees in Southeastern Australia. For. Sci. 2007, 53, 426-434.

54. Frivold, L.H.; Frank, J. Growth of mixed birch-coniferous stands in relation to pure coniferous stands at similar sites in south-eastern Norway. Scand. J. For. Res. 2002, 17, 139-149.

55. Kuo, Y.L.; Fan, K.S.; Hwang, C.W.; Lee, Y.P.; Wu, H.L.; Tsay, R.F. Gas exchange potential in sun-exposed leaves of 30 broadleaf tree species in Taiwan. Taiwan J. For. Sci. 2004, 19, 375-386. (In Chinese)

56. Kanowski, J.; Catterall, C.P. Converting Stands of Camphor Laurel to raInforest: What are the Costs and Outcomes of Different Control Methods? Griffith University: Nathan, Australia, 2007; p. 16.

57. Kanowski, J.; Catterall, C.P.; Neilan, W. Potential value of weedy regrowth for rainforest restoration. Ecol. Manag. Restor. 2008, 9, 88-99.

58. Dobrowolska, D.; Hein, S.; Oosterbaan, A.; Wagner, S.; Clark, J.; Skovsgaard, J.P. A review of European ash (Fraxinus excelsior L.): Implications for silviculture. Forestry 2011, 84, 133-148.

59. Perry, E.; Hickman, G.W. A survey to determine the leaf nitrogen concentrations of 25 landscape tree species. J. Arboric. 2001, 27, 152-159.

60. Wiedemann, E. Ertragskundliche und Waldbauliche Grundlagen der Forstwirtschaft; J. D. Sauerländer's Verlag: Frankfurt, Germany, 1950.

61. Mitscherlich, G. Wald, Wachstum und Umwelt. v. 1, Form und Wachstum von Baum und Bestand; J. D. Sauerländer's Verlag: Frankfurt, Germany, 1978.

62. Welham, C.; Seely, B.; Kimmins, H. The utility of the two-pass harvesting system: An analysis using the ecosystem simulation model FORECAST. Can. J. For. Res. 2002, 32, 1071-1079.

63. Richards, A.E.; Forrester, D.I.; Bauhus, J.; Scherer-Lorenzen, M. The influence of mixed tree plantations on the nutrition of individual species: A review. Tree Physiol. 2010, 30, 1192-1208.

64. Oliver, C.D.; Larson, B.C. Forest Stand Dynamics; McGraw-Hill: New York, NY, USA, 1990.

65. Kimmins, J.P. Forest Ecology: A Foundation for Sustainable Forest Management and Environmental Ethics in Forestry, 3rd ed.; Pearson Prentice Hall: Upper Saddle River, NJ, USA, 2004. 
66. Blanco, J.A. Forests may need centuries to recover their original productivity after continuous intensive management: An example from Douglas-fir stands. Sci. Total Environ. 2012, 437, 91-103.

67. Hooker, T.D.; Compton, J.E. Forest ecosystem carbon and nitrogen accumulation during the first century after agricultural abandonment. Ecol. Appl. 2003, 13, 299-313.

68. Blanco, J.A.; Zavala, M.A.; Imbert, J.B.; Castillo, F.J. Sustainability of forest management practices: Evaluation through a simulation model of nutrient cycling. For. Ecol. Manag. 2005, 213, 209-228.

69. Josefsson, T.; Olsson, J.; Östlund, L. Linking forest history and conservation efforts: Long-term impact of low-intensity timber harvest on forest structure and wood-inhabiting fungi in northern Sweden. Biol. Conserv. 2010, 143, 1803-1811.

70. Gárate, M.; Blanco, J.A. Importancia de la caracterización de la masa de raíces en la simulación de ecosistemas forestales. Revista Ecosistemas 2013, 22, 66-73. (In Spanish)

(C) 2015 by the authors; licensee MDPI, Basel, Switzerland. This article is an open access article distributed under the terms and conditions of the Creative Commons Attribution license (http://creativecommons.org/licenses/by/4.0/). 